\title{
Erratum to: Wage dynamics and promotions inside and between firms
}

\section{António Dias da Silva · Bas van der Klaauw}

Published online: 6 October 2011

(C) Springer-Verlag 2011

\section{Erratum to: J Popul Econ (2011) 24:1513-1548 DOI 10.1007/s00148-010-0336-6}

The original version of the article unfortunately contained a mistake. The order of authors on the published version was incorrect due to an error introduced by Springer. The publisher regrets this error.

The correct order of authors is shown above.

The online version of the original article can be found at http://dx.doi.org/10.1007/s00148-010-0336-6.

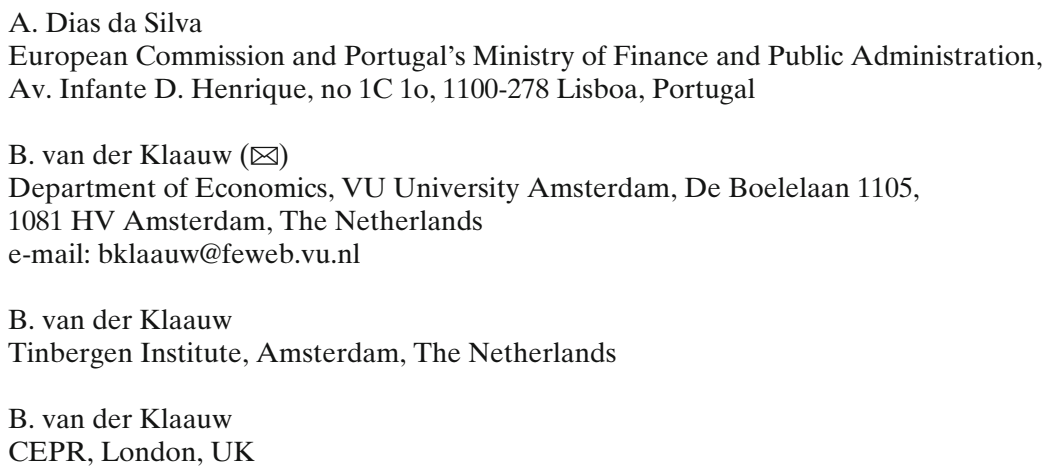

